Christine Stilwell

\begin{abstract}
This paper reports on the information needs of learners in the Emzamweni High School in Inadi near Pietermaritzburg Msunduzi in KwaZulu-Natal, South Africa. A preliminary report, it presents the outcomes of a survey based on the critical incident approach. Students in the Post Graduate Diploma in Information Studies Programme conducted interviews over a two year period from 2001 to 2002. The students were enrolled for an exemplar in the Community Higher Education Service Partnerships project in community based learning at University of Natal, Pietermaritzburg. The project was hence an exercise in training student researchers and is useful for what it revealed about the critical nature of the needs of these learners.
\end{abstract}

\title{
Introduction And Background To The Study
}

This is a preliminary report on the information needs of learners in the Emzamweni High School in the community of Inadi near Pietermaritzburg-Msunduzi in KwaZulu-Natal, South Africa. It brings together data collected by Post Graduate Diploma in Information Studies (PGDIS) students over a two year period, 2001 to 2002. The students were enrolled for the Information Users and Use module, an exemplar in the Community-Higher Education Service Partnerships (CHESP) project on the Pietermaritzburg campus of the University of Natal (UN). As the study is largely qualitative the voices of the students are reported verbatim in their comments and reflections. In this section key players are introduced and information and information needs defined.

\section{University of Natal and the Information Studies Programme}

The University of Natal (UN) was founded in Pietermaritzburg as the Natal University College in 1910 (Brookes \& Webb, 1965, p. 247). In its present configuration the university straddles four campuses, Howard College and the Nelson R. Mandela School of Medicine in Durban, the Edgewood campus (since 2001) and the Pietermaritzburg campus. The University is merging with the University of Durban Westville, a formerly disadvantaged institution set up in the apartheid era as a university for South Africans of Indian origin.

The UN programme in Information Studies, on the Pietermaritzburg campus, is one of 15 such South African departments (Hart, 2002, p. 35) and offers a full suite of qualifications commencing with an undergraduate module in Information Literacy which is part of an Access Programme, created to facilitate access to a degree for students who are perceived to have potential but have low university entrance level points. Higher Degree programmes in Information Studies, the B.Bibl Honours, Master's and Doctoral programmes were introduced in 1978. Other foci include the Diploma in School Librarianship, and Postgraduate Diplomas in Museum Studies and in Records and Archives Management. 
The first professional qualification, PGDIS, requires a Junior Degree in any field as a prerequisite. Modules offered in this Diploma formed part of the community based or service learning initiative introduced into UN in 2001 . The CHESP initiative, described in the next section, provided an opportunity for the UN to formally implement community based learning. Becker (2000) and De la Pena McCook (2000), for example, have made the case for a service learning model in Library and Information Studies curricula.

\section{CHESP and Community Based Learning}

The theoretical framework on which the concept of community based learning in this context is that of a 'scholarship of engagement' (Boyer, 1996), which was further developed by Bawden (1999) with CHESP in mind. This idea of engagement involves a connection between university-based lectures and research projects with off-campus sites of knowledge generation and action. The core purpose of this engagement is to address pressing issues in society, responding to the challenges of social development and democratic citizenship (Boyer, 1996). Funded by the Joint Education Trust and the Ford Foundation, CHESP is a national initiative, aimed to further the transformation of South African universities towards sustained community engagement in their curricula, to develop local communities as sites of civil society, and to enhance the provision of appropriate services in these communities (Nuttall, 2001). The CHESP concept of community learning involves a dynamic process, linking communities and their priorities, issues and problems with student learning, research and development. In this model a third element constitutes the service provider.

In this case the proposed service provider was Education Library, Information and Technology Services (ELITS), the government department responsible for the planning and infrastructure of school libraries and for their provision and maintenance. It was envisaged that the service provider would work with the University to provide advice and guidance for the research and would ultimately gain by the utilisation of the results for the implementation of a functioning school library, to the benefit of the community. Although very keen to participate, for various reasons the service provider was unable to take an active role in the process.

The CHESP core group of the Pietermaritzburg campus focused on the Inadi community, a rural settlement comprising 18 villages on the outskirts of the city of Pietermaritzburg-Msunduzi. The Emzamweni High School in Inadi was chosen as the service learning site for a variety of reasons, including the fact that it is a rural area and historically disadvantaged. In the late 1980s this community was badly affected by politically motivated violence. Myende, a student in 2002 and a resident in the area reports how "learners were killed on their way to and from school" (Myende, 2002, p.c3). As late as the early 1990s two new administration buildings at the school were set on fire.

At the time of the survey the school had approximately 700 learners and 22 teachers. It had an excellent Matriculation pass rate and many of its matriculants pursued tertiary level studies. The library, however, from personal observation was in a sad state of neglect and little suitable material was available. Polak (2002, p. 5) from the class of 2002, reports it was "not conducive to a learning situation". The Information Studies component of the CHESP project aimed at assessing the information needs of the Emzamweni High School learners. Information and information need are defined in the next section.

\section{Information and information need}

Information is defined by Kaniki (2001, p. 191) as "ideas, facts, imaginative works of the mind and data of value potentially useful in decision making, question answering, problem solving etc". The term "information need" is related to the term "use" which is described next. Use implies a response to need which Dervin (1980) sees as a state that arises within a person thereby suggesting some kind of gap that requires filling. As Kaniki (2001, p. 188) suggests, such general needs may be physiological, psychological, social and economic. He adds that in our daily life:

Every person is faced with decision making situations or problem solving situations or questions. These may either be abstract, cognitive or real. They may be mental or physical or both. However, because of one's experience or acquired knowledge, which is an accumulation of information with specific application, some of these situational problems, decision making processes or questions become 'normal'. In other words, a person would either have developed ready solutions to such 'normal problems' or have ideas as to how to solve or seek assistance or solutions to such 'problems' (Kaniki, 2001, p. 191). 
There are, however, several situations or instances in which a person or groups of persons encounter problems, decision-making and, or, question answering situations but do not have ready "solutions" for them: "In other words the person or community experiences or develops a gap, or is in a state of lacking some commodity, which must be filled" (Kaniki, 2001, p. 191). The process of seeking information and the degree to which the seeker satisfies the need depends upon the level of information literacy or information seeking, searching and use, knowledge and skills an individual possesses (Kaniki, 2001, pp. 191-2). In earlier studies, Faibisoff \& Ely (1979) and Krikelas (1983) drew on a psychological explanation to describe a state of information need. Kaniki (2001, p. 192) explains: "This state of uncertainty requires information as a stimulus to create a change in one's level or degree of uncertainty". He defines information need as "the state of lack of a desirable requisite or commodity (namely information) necessary to deal with a situation, as an individual (or as a member of a given community) sees fit". In order to meet such information need, the level and nature of uncertainty needs to be assessed. This assessment requires information literacy on the part of the information seeker and skill from the information professional. The appropriateness of the information provided in response to a need depends on the extent to which it resolves the given need and here the seeker is the judge.

A need for information can be recognised or unrecognised, expressed or unexpressed. Some information needs may be recognised by the information seeker him/herself or by the information expert in engaging with the seeker. The former and the latter may have to "work together towards 'disentangling' and establishing the actual need" (Kaniki, 2001, p. 192). In some cases the problem is accepted as a normal part of life and no remedy is sought (Fairer-Wessels, 1990). This might well apply to those learners in the Emzamweni study who were unable to articulate a problem or who did not try to resolve an identified problem. Very little research has been done on the information needs of, and access to information for, high school learners, particularly in rural and quasi rural situations.

In 1994, from her Johannesburg base Millward identified various areas of information need for South African youth living in the then townships. These were careers, youth rights, child abuse, rape and money matters, sex, family life, HIV/AIDS, academic stress, health, fashion and drugs as priorities with violence, discrimination, religion, peer pressure, alcohol and homosexuality scoring lower.

In 2000 Rubushe reported on a survey of 117 Grade 11 learners from five high schools in Mdantsane, Eastern Cape. Drawn using a stratified random sample, the learners in Rubushe's study required information for self-education, reaching a decision and solving problems. They were less aware of issues such as HIV/AIDS, sex, drugs and alcohol than the literature suggested. Informal sources such as parents and friends were used to access information as well as teachers, books, newspapers and magazines (Rubushe, 2000).

A 2002 survey of user and non-users carried out for Ethekwini Municipal Libraries by Urban Econ used individual and household surveys and focus group discussions to capture data. This report suggests that the following topics should be included in the book stock for youth: anger, anxiety, grieving, stigma, controlling stress, health risks, death, failure, selfesteem, tolerance, gangs, being a runaway, discrimination and bias incidents, cross cultural and interracial relationships, sexuality and sexual identity, date rape and sexual abuse, dysfunctional families and family violence, suicide and drugs. Some findings from this research are discussed below (Ethekwini Municipal Libraries, 2002, pp. 23-24).

\section{Research Methodology And Procedures: The Information Needs Assessment Survey}

This section reports on the research methodology used and sketches the procedures involved.

\section{The critical incident or anomalous state of knowledge (ASK) approach}

Information needs have been seen to be embedded in behaviour or patterns of seeking and using information, hence the study of information seeking behaviour and information. One of the techniques which have been developed is the "anomalous state of knowledge approach" (ASK) approach (Kaniki, 2001, p. 195). This is a qualitative approach which examines how people or communities seek information concerning situations about which their knowledge is incomplete. Fisher \& Oulton (1999, p. 116) point out that this approach has been used in a number of instances in library and information management but that current knowledge of the method and its potential applications seem more 
limited than the method deserves, particularly in Britain. Insight into the information needs of the population of learners in this study was gained from a survey using the critical incident or ASK approach (Kaniki, 2001, p. 195).

The use of the critical incident approach in library use studies is a way of focusing the respondent's mind and of providing data on a specific occurrence. It is hence a more useful approach than seeking generalised accounts of library use (Fisher \& Oulton, 1999, p. 117). The critical situations may be problem situations, decision-making or question answering situations. Respondents are asked why and how they seek information and through this process various common situations or the critical tasks of a community are identified. The initial questions are broad to enable the respondent's unprompted selection of a particular area of need. For this reason some of the information seeking situations described below appear as general rather than immediately information related in the first instance.

The ASK approach was used in the study to enable the identification of areas of concern to the learners, that is their critical information seeking situations. Through the use of content analysis the critical instances or situations were grouped together and quantified and thus measured to determine their levels of significance within the limitations of the study. Criticism of the ASK approach revolves around its dependence on the respondent's ability to remember the critical instances, however, as Kaniki (2001, p. 195) argues, people will often remember what they consider to be critical to them. He raises a second criticism that the ASK approach does not follow up on the use made of the information obtained. The best way to assess the information required and the value of the information provided is by measuring use made of the information and the impact made by its provision (Blom, 1983; Kaniki, 2001). The current study, as an exploratory one, did not assess impact. Respondents were asked, however, about the extent to which they were satisfied with the result of the information seeking behaviour.

\section{Research procedures}

During April 2001 and March 2002 the survey was carried out in two phases with the learners of Emzamweni High School and with the help of school and community representatives. An interview schedule based on that designed by Kaniki (1995) and used in a study of two South African rural areas, was adapted for this purpose. Two types of questions were used, structured pre-coded questions and open questions that required content analysis. For the data collection staff and students travelled to Emzamweni High School, where the students conducted face-to-face interviews with a stratified sample of learners.

In 2001 fifteen students conducted interviews with 244 learners drawn from grades 8 to 12 . The interviews, mainly in English, with the grade 8s and 9s were not as productive as they should have been so in 2002 only grades 10 to 11 were interviewed. These interviews were conducted by a smaller class of six students with 72 learners, yielding an overall sample of 316 of a total population of approximately 700 learners in the school, that is a sample of $45 \%$ of the population. Equal numbers of boys and girls were drawn from the classes targeted.

Students spent about ten minutes interviewing each learner assigned to them. As the data collection fell on a day for speaking English and as the School was keen to have this medium used, the interviews were conducted in English much against the better judgement of the authors. Zulu is the home language of the learners. When language problems occurred particularly with the younger learners, the students used Zulu. Translation into Zulu was provided for foreign students by the community representatives.

Using the critical incident technique, the interviewer asked learners to identify a recently experienced problem or information-seeking situation or critical incident. These are reported on in Table 1. They were also asked about the information channels which they had used in resolving the problem (see Table 2) and whether or not they were happy or satisfied with the outcome of this information seeking exercise.

The students analysed the data using content analysis for the open questions and then descriptive statistics in terms of calculating frequencies and percentages. They wrote a report outlining the research process, interpreting the results and providing conclusions and recommendations. This report brings together the findings of these reports from the two phases. In the second year a reflection paper was introduced to capture the students' personal responses to their experience of doing the research and these papers provided interesting insights into their learning processes. 


\section{The Learners And Their Information Needs}

The learners ranged in age from 12 to 25. The older than usual school-going age of the learners in upper age groups is explained by the exclusion of learners from school during the struggle years and the need to accommodate them at the present time.

The learners' critical incidents or information seeking situations were as follows. There were 31 learners who could not give an instance of a problem situation. This could possibly relate to a situation identified by Fairer-Wessels (1990) in a study of urban black women in Mamelodi in the then apartheid South Africa. The situation of not taking action in response to needs, according to Fairer-Wessels (1990, p. 363), is because the need has become "so entwined" with daily life that the respondents do not experience it as a problem. While the illiterate women in her study were seen as being especially likely to just live with the situation, Fairer-Wessels argues that the urban black women generally were unaware of their needs and did not articulate them. They did not see the problems as anything that could be solved because they had not learnt to identify problems, search for alternative solutions and attempt to solve them. They merely lived with, and experienced, the situation. One such respondent is reported on by Madlala (2002a, p. 10) from the class of 2002. The learner reported a problem at home in that;

she was required to do all the house chores after school and ended up having little time to study. The environment at home was not conducive to her studying and she was doing her Matriculation. She was worried that she would fail her Matriculation if things continued in this way. She had not tried to seek help and share her problem with friends as they seemed to be having the same problem.

Such respondents would fall into Kaniki's (2001, p. 192) category of those who encounter problems but are not sufficiently information literate to address them. They experience a state of lacking information but are unable to propel themselves towards finding a solution. Neither do they have ready access to information intermediaries who could assist in addressing the lack of information.

On the other hand some of these respondents were drawn from the Grade 8 and 9s surveyed in 2001 who had experienced problems with communicating in English. 


\begin{tabular}{|c|c|c|}
\hline Situation & Number & Percentage \\
\hline Access to information (library inadequate) & 76 & 24 \\
\hline Difficulties with school subjects & 56 & 18 \\
\hline Abuse & 24 & 8 \\
\hline Financial problems & 20 & 6 \\
\hline Crime (including rape) & 17 & 5 \\
\hline \multicolumn{3}{|l|}{ Inadequate facilities } \\
\hline (laboratory, sports, telephone, electricity) & 13 & 4 \\
\hline \multicolumn{3}{|l|}{ Violence } \\
\hline (including corporal punishment and witchcraft) & 12 & 4 \\
\hline Unemployment (parents) & 11 & 3 \\
\hline Intimidation/bullying/peer pressure & 11 & 3 \\
\hline Health problems & 6 & 2 \\
\hline Inadequate or no computer skills & 5 & 2 \\
\hline School dirty & 5 & 2 \\
\hline Coping with death & 5 & 2 \\
\hline HIV/AIDS & 5 & 2 \\
\hline Substance abuse & 4 & 1 \\
\hline Communication with parents and teachers & 3 & 1 \\
\hline Parenting poor & 3 & 1 \\
\hline Domestic chores & 3 & 1 \\
\hline Lateness for school & 2 & 1 \\
\hline Harmful gossip & 2 & 1 \\
\hline Environmental problems & 1 & 0 \\
\hline Abusive language on TV & 1 & 0 \\
\hline Total & 285 & 90 \\
\hline
\end{tabular}

The high number of learners raising access to information as their critical situation could partly be explained by their possibly being cued by the nature of the survey to raise such information issues. Many, however, gave examples of visiting the library in the city centre and this need relates to the next highest scored concern about difficulty with school subjects. While the Urban Econ survey was based in the Ethekweni Metropole and hence in an area very different from that of Emzamweni, among the users of 13 years and older, school projects scored highest among the items of most commonly required information, thus echoing the top areas of need in the Emzamweni survey (Ethekweni Municipal Libraries, 2002, p. 50). The needs reflected in this Emzamweni survey confirm the areas identified as being of key interest to the youth by the Ethekweni report in spite of the differences between the urban and rural settings. This echoes Lund's observation (1998, p. 8) that the urban-rural dichotomy is less helpful with regard to characterising poverty as vast informal settlements mushroom around major cities and inner city areas are now characterised by deep poverty, as are the peri-urban settlements that surround many cities.

Several of the Emzamweni learners' concerns could be seen as linked, such as the unemployment of parents and the burden of domestic work, that hampered school work. Unemployment and the legacy of violence in the area relate to intimidation and bullying in the school and to perceptions of crime being a problem. The students were especially concerned that the learners had had little or no access to counselling to assist them in coming to terms with their experiences of violence. 


\section{Information channels used}

The information channels used by the learners to seek information were as follows. More than one channel might have been used, hence although there were 37 non-responses, there were 285 instances of various channels being used. None of the respondents mentions using a library although some have used the type of material supplied by libraries. Myende (2002, p. 14), an alumnus of the school, now revisiting it as a university student, offers some insight into the non-use of libraries with comments on his attitude as a learner:

In my mind libraries were for those special people, not for me, and the fact that there was no one library around, the appetite for using it was not stimulated.

\begin{tabular}{|lcc|}
\hline Table 2: Information channels used N=285 & & \\
\hline Channel & Number & Percentage \\
\hline Teacher & 72 & 25 \\
\hline Radio and television & 57 & 20 \\
\hline Friend or neighbour & 47 & 17 \\
\hline Relative & 43 & 15 \\
\hline Newspapers & 26 & 9 \\
\hline Books & 15 & 5 \\
\hline Ward Councillor & 10 & 4 \\
\hline Church, Women's or HIV Awareness Group & 7 & 3 \\
\hline Own experience & 3 & 1 \\
\hline Police & 2 & 1 \\
\hline Religious leader & 2 & 1 \\
\hline Doctor & 1 & 0 \\
\hline Total & $\mathbf{2 8 5}$ & $\mathbf{1 0 0}$ \\
\hline
\end{tabular}

Groups, such as the HIV/AIDS awareness group operating at the School, had been used by seven (3\%) learners. A high proportion of the learners $183(64 \%)$ had used interpersonal sources. Teachers were top at $72(25 \%)$ and were thus significant sources of information for the learners. Other interpersonal sources such as friends, neighbours and relatives followed. Personal contacts are an important source of information for information seekers from many occupational groups and this includes learners. Lamoral $(2001$, p. 184) in an audit of the sources favoured by welleducated users of the Institute for Commercial Forestry Research (ICFR) Library attached to the University of Natal, Pietermaritzburg-Msunduzi, found that personal contacts ranked as the second preferred information source. Lamoral comments in a way that is useful in planning services to learners, too, that this preference indicates the need to personalise the information services provided. She quotes Maguire \& Kench (1981 in Lamoral, 2001, p. 184) who state that "the preferred means of receiving information is person to person".

Forbes (1999) in a study of the information needs of domestic workers in Clarendon, Pietermaritzburg-Msunduzi, found that the most heavily used information channel was also personal communication with relatives, friends, employers, co-workers and the police serving as sources. These workers sought information from the providers they knew best whether or not these were the best source of information. Fairer-Wessels (1990, p. 365) points out the inadequacy of personal sources and the need for information outlets that are accessible and adequate.

What seems to be crucial is that personal sources are a favoured information channel even when access to a range of sources is available. If, however, personal sources are used it is important that the source or person has expertise in the relevant area as in the case of the ICFR clientele. In the situations of the poorly educated women cited in FairerWessels's study this did not appear to be the case. In the case of the Emzamweni High School learners the teachers were likely to be an adequate source of information but their skills in the more problematic areas such as counseling about violence, rape and abuse would need to be augmented by reference to professionals in fields such as psychology, health and law. The learners in the current study, while enjoying a higher level of education, did not appear to have ready 
access to expert sources or did not use them. Myende (2002, p. 12) explains: "The families themselves do not have the knowledge to help themselves in getting information that could be useful to them so that they can help their children".

Another 57 (20\%) used the mass media with radio scoring highest here. Newspapers featured at $269 \%$ ). A free weekly supplement to the daily Natal Witness called Echo, was available but was possibly difficult to access from the School. Surprisingly, given the circumstances, 15 respondents (5\%) had used books.

Three had relied on their own experience. Civic figures such as the Ward Councillor rated 10 (4\%). Religious leaders featured at the low level of two (1\%).

\section{Levels of satisfaction with the outcome of seeking information}

The learners were asked about their levels of satisfaction or lack thereof with the outcome of the information seeking. For the 221 who responded, the responses were fairly evenly spread between those who were satisfied 115 (52\%) and those who were not 106 (48\%).

Some of those who were satisfied were reported on as follows:

A male learner had no one to pay his school fees as both parents were unemployed. He talked to a male teacher about his problem and the teachers found him a temporary job. Every Saturday he works as a gardener to pay his fees. He reported that the help he got from the teacher was a 'great help' and he 'learned a lot from the teacher' (Madlala, 2002a, pp. 10-11).

Another male learner had a problem with his class teachers so;

he joined a group of gangsters, one of whom was a boy from the same school who was against the teacher on the grounds that the teacher was strict. He later changed his mind and decided to speak to the teacher and apologise after being advised by another teachers at the school (Madlala, 2002a, pp.10-11).

Some of the dissatisfied learners were reported on as follows:

A grade 11 learner complained that he had repeated this grade for the third time. He had tried to get help from his mother but she did not know what to do (Madlala, 2002a, pp. 10-12).

Another had a problem in that:

The books he wanted to read were written in English in difficult vocabulary, for instance, a book on children's rights. He had tried to get help from television programmes but did not get sufficient help

(Madlala, 2002a, pp. 10-2).

Nearly half the learners were not satisfied with the outcome of their information seeking and this is a major cause of concern in situations as serious as those reported, involving abuse and intimidation. The use of interpersonal sources of information requires further study. Myende's comments (2002, p. 13) on the learners reveal the critical nature of the situation: "Some of them are gradually giving up on living, they believe that life is not for them. They feel no need to live". 


\section{Conclusions And Recommendations}

The PGDIS students recognised the urgent need for counselling and with staff liased with the CHESP partners from the School of Psychology on the local campus about these concerns, particularly about the incidence of rape and the inability of learners to achieve closure about their own part in the political violence in the area. Support Centres staffed by paralegals from the University of Natal's Centre for Criminal Justice are available at centres as nearby as Taylor's Halt and Plessislaer to provide legal advice and referral to experts in the city. Madlala (2002b, p. 2) comments: "I think psychologists and social workers are needed to help the learners get counselled and get people who can understand their problems and spend some time with them to build a certain communication between the child and the parent".

An obvious need is for library provision at the school. The existing facility had been improved by volunteers connected to the Information Studies Programme some years earlier but had again fallen into disrepair. The staff member responsible for the library, while she had some school library training, seemed unequal to the task and also lived many kilometres away in Ethekwini. The provision of electricity to the school by April 2002 widened the range of options possible in a future improved facility. Ideally the school library should be linked to Information and Communication Technology initiatives planned for the area. These are the Super Centres Telkom Project and the Thintana Computers In Schools Project. Emzamweni is being considered for the Thintana Project which puts 15 computers in a school, fully connected and electronic-mail for every student and staff member as well as Internet access (Du Toit, 2001). Sustained intervention by a service provider is, however, required to maintain and upgrade the facility. The learners recognise the need for a library and are highly likely to be motivated users.

In consultation with Masters students from Psychology the students designed and produced career information pamphlets for the learners focussing on the areas they had requested information about. These were intended to inform choices about future career options. With colleagues from the University's Main Library in Pietermaritzburg they produced visual display material around the theme of library literacy for Careers Day held by the School of Psychology staff at the School.

Concerning the success of this part of the CHESP initiative as a learning model, comment from student reflection papers are critical but generally positive.

Nene (2002, p. 1) from the class of 2002 wrote:

Although this was supposed to be just a study for me it was an eye-opening experience. I was deeply touched by a particular learner who had no employed people at home so he has never paid school fees and relies on neighbours, friends and relatives for food. He was so eager to get an education despite his circumstances ...

Miya (2002, p. 1) commented that one respondent had come to Emzamweni to get away from a drug habit which had led him to use cocaine. At Emzamweni learners were more likely to abuse alcohol and dagga than harder drugs. Miya attributed this substance abuse to learners being unable to solve their problems and lacking the information necessary to do so. In spite of this worrying revelation for Miya this experience was "exciting because it was my first opportunity to conduct a survey, interviewing learners, and gathering and classifying the critical incidents experienced by the learners".

Finally, in contrast to the impression given by Myende (2002) above, another facet of this complex situation is revealed by Landsberg (2001, pp. 8-9) from the class of 2001. She comments:

I was most impressed with the learners' zest for life. It was an eye-opener to see the learners in a disadvantaged school so content with the little they had. I walked around the school during the lunch break and visited a classroom which had murals and posters on the walls highlighting Aids awareness. There were vegetable and flower gardens in the grounds of the school and the learners were happily weeding the gardens. My memories of Emzamweni High School will be the positive attitude, the laughter and the voices of learners during their choir practice. 
In conclusion, within the limitations of this being a training exercise using student researchers and the difficulties of collating data from a variety of student reports, the study was successful for what it revealed about the needs of this group of learners. To the authors' knowledge no similar studies exist in the province. As a result of the substantial stratified sample the findings can be generalised to other similar situation but the limitations of this research as a teaching exercise with results based on the experimental work should be recognised. The last word goes to Zuma (2002, p. 2) from the class of 2002:

I would like to see a bigger study being conducted to assess the needs of these learners, when more time will be allocated and one can expect a bigger picture of the problem situations of these learners. But I don't undermine this study we conducted - it did serve its purpose.

\section{Acknowledgements}

This paper brings together the information needs assessment reports of the Class of 2001: Goitsemang Gladness Isaac, Annette Landsberg, Refilwe Cynthia Masondo, Eng Sealogane Mpotokwane, Bridget Smangele Mpungose, Nontokozo Myende, Nompumelelo Hazel Ndlovu, Sibongile Nene, Lefuma Evodia Sejane, Thobile Rosemary Sithole, Maxwell March Teputepu, Ntombifuthi Doris Vezi, Lilian Nomusa Zuma, Simangele Deborah Zuma and Bongekile Goodness Zwane, and the Class of 2002: Monica Nonkululeko Madlala, Raphael Zethembe Miya, Zibuse Myende, Jabulile Laughday Elizabeth Nene, Fiona Margaret Polak,and Mzomuhle Jeffrey Zuma.

It is dedicated to the memory of Bongekile Goodness Zwane and Maxwell March Teputepu, Class of 2001, whose lives so full of promise, have already tragically ended.

\section{References}

Bawden, R. (1999). The community challenge: the learning response. Paper presented to CHESP Leadership Capacity Building Programme Seminar, Cape Town, December.

Becker, N. J. (2000). Service learning in the new curriculum: preparing LIS students for the next millenium. Journal of Education for Library and Information Science, 41(4), 85-93.

Blom, A. (1983). The task performance of the scientist and how it affects an information service. Mousaion, Series III $1(1), 3-43$.

Boyer, E. (1996). The scholarship of engagement. Journal of Public Service Outreach, 1 (11), $11-20$.

Brookes, E.H. \& Webb, C. de B. (1965). A history of Natal. Pietermaritzburg: University of Natal Press.

De la Pena McCook, K. (2000). Reconnecting library education and the mission of community. Library Journal, 125 (14), 164-65.

Dervin, B. (1980). Information as a user construct: the relevance of perceived information to synthesis and interpretation. In S.A. Ward \& L.J. Reed (Eds), Knowledge, structure and use (pp. 155-83). Philadelphia, Temple University Press.

Du Toit, M. 2001. E-mail letter concerning ICT possibilities in the Inadi area. Pietermaritzburg, April.

Ethekweni Municipal Library Services. (2002). User and non-user survey. Ethekweni: Urban-Econ.

Faibisoff, S. \& Ely, D.S.(1979). Information and information needs. In D.W. King (Ed), Key papers in the design and evaluation of information systems (pp. 270-84). New York: Knowledge Industry. 
Fairer-Wessels, F. (1990). Basic community needs of urban black women in Mamelodi, Pretoria, South Africa. South African Journal of Library and Information Science, 58(4), 359-69.

Fisher, S. \& Oulton,T. (1999). The critical incident technique in library and information management research. Education for Information, 17, 113-25.

Forbes, C. (1999). The information needs of domestic workers employed in Clarendon, Pietermaritzburg: an assessment. Innovation: a Journal of Appropriate Librarianship, 19, 8-17.

Hart, G. (2002). The African Renaissance and children's literature: is South African librarianship abdicating its role? South African Journal of Libraries and Information Science, 68(1), 29-38.

Kaniki, A-M. (1995). Exploratory study of information needs in the Kwa-Nganase (Natal) and Qumbu (Transkei) communities of South Africa. South African Journal of Library and Information Science, 63 (1), 9-17.

Kaniki, A-M. (2001). Community profiling and needs assessment. In C. Stilwell, A. Leach \& S. Burton (Eds), Knowledge, information and development: an African perspective (pp.187-99). Pietermaritzburg: School of Human and Social Studies, University of Natal.

Krikelas, J. (1983). Information seeking behavior: patterns and concepts. Drexel Library Quarterly, 19 (Spring), 5-20.

Lamoral, D. (2001). An evaluation of information provision at the Institute for Commercial Forestry Research, South Africa: the findings of an information audit. Journal of Librarianship, 33(4), 177-90.

Landsberg, A. (2001 ). An investigation of the information needs of the learners at Emzamweni High School, Inadi, Pietermaritzburg. Unpublished PGDIS paper. Pietermaritzburg: University of Natal, School of Human and Social Studies.

Lund, F. (1998). Who's in and who's out: the effects of poverty and inequality on participatory and institutional development. Durban: Olive. Avocado Series No. 2.

Madlala, M. (2002a). An investigation into the feasibility of establishing an information support strategy for Emzamweni High School in the Inadi Community. Unpublished PGDIS paper. Pietermaritzburg: University of Natal, School of Human and Social Studies.

Madlala, M. (2002b). Reflection paper on the information needs assessment. Unpublished PGDIS paper. Pietermaritzburg: University of Natal, School of Human and Social Studies.

Millward, J. (1994). Young adult library services in Johannesburg: addressing the needs of teenagers in a multi-cultural society in transition. International Review of Children's Literature and Librarianship 9 (2): 57-72.

Miya, R. (2002). Reflection paper on the information needs assessment. Unpublished PGDIS paper. Pietermaritzburg: University of Natal, School of Human and Social Studies.

Myende, Z. (2002). Information needs of High School Learners at the Emzamweni High School, Inadi, KwaZulu-Natal. Unpublished PGDIS paper. Pietermaritzburg: University of Natal, School of Human and Social Studies .

Nene, J. (2002). Reflection paper on the information needs assessment. Unpublished PGDIS paper. Pietermaritzburg: University of Natal, School of Human and Social Studies.

Nuttall, T. (2001). Moving community-based learning into the mainstream university curriculum: South African opportunities and challenges. Paper presented to the Social Science Curriculum Reform Conference, Ford Foundation Social Sciences Project, Pretoria, 26 September. 
Polak, F. (2002). An exploratory study of the information needs of High School Learners at the Emzamweni High School, Inadi, KwaZulu-Natal. Unpublished PGDIS paper. Pietermaritzburg: University of Natal, School of Human and Social Studies.

Rubushe, B. (2000). An exploratory study of the information needs of secondary school students in Mdantsane Township, Eastern Cape. Masters in Information Studies thesis. Pietermaritzburg: University of Natal.

Zuma, M.J. (2002). Reflection paper on the information needs assessment. Unpublished PGDIS paper.

Pietermaritzburg: University of Natal, School of Human and Social Studies.

\section{Biographical Notes}

Christine Stilwell is Professor and Director of Discipline and Fiona Bell, Lecturer in Information Studies, School of Human and Social Studies, University of Natal, Private Bag X01, Scottsville, Pietermaritzburg. Stilwell researches, supervises research and lectures in the area of information needs assessment and co-ordinates the Doctoral Programme in Information Studies. She co-edited the book Knowledge, information and development: an African perspective.

Email stilwell@nu.ac.za

Fiona Bell co-ordinates the Post Graduate Diploma in Information Studies and in this capacity has participated in and given papers about community based learning. Her fields of expertise are cataloguing, classification and reference work, traditional and online. She researches in education and training for Library and Information Studies and supervises research in this area. Email: bellf@nu.ac.za 